Supporting Information for:

\title{
New pathways for Asphaltenes Upgrading Using Oxy-Cracking Process
}

\author{
Maryam Ashtari, ${ }^{\mathrm{a}, *}$ Lante Carbognani Ortega, ${ }^{\mathrm{a}}$ Francisco Lopez-Linares, ${ }^{\mathrm{a}, \mathrm{b}}$ Abdelatif Eldood, ${ }^{\mathrm{a}}$ \\ Pedro Pereira-Almao ${ }^{\text {a }}$ \\ a Department of Chemical \& Petroleum Engineering, Schulich School of Engineering University of Calgary, \\ Calgary, Canada, T2N1N4 \\ b. Present address; Petroleum and Materials Characterization Unit, Chevron Energy Technology Company, \\ 100 Chevron Way, Richmond, California, 94801, United States
}

\section{List of Figures.}

Figure S1. Model and experimental products and reactants carbon mass at $200^{\circ} \mathrm{C}$, a. asphaltene carbon mass, b. organic carbon mass in liquid, c. inorganic carbon mass in liquid plus carbon in $\mathrm{CO}_{2}$ gas.

Figure S2. Model and experimental products and reactants carbon mass at $210^{\circ} \mathrm{C}$, a. asphaltene carbon mass, b. organic carbon mass in liquid, c. inorganic carbon mass in liquid plus carbon in $\mathrm{CO}_{2}$ gas. 

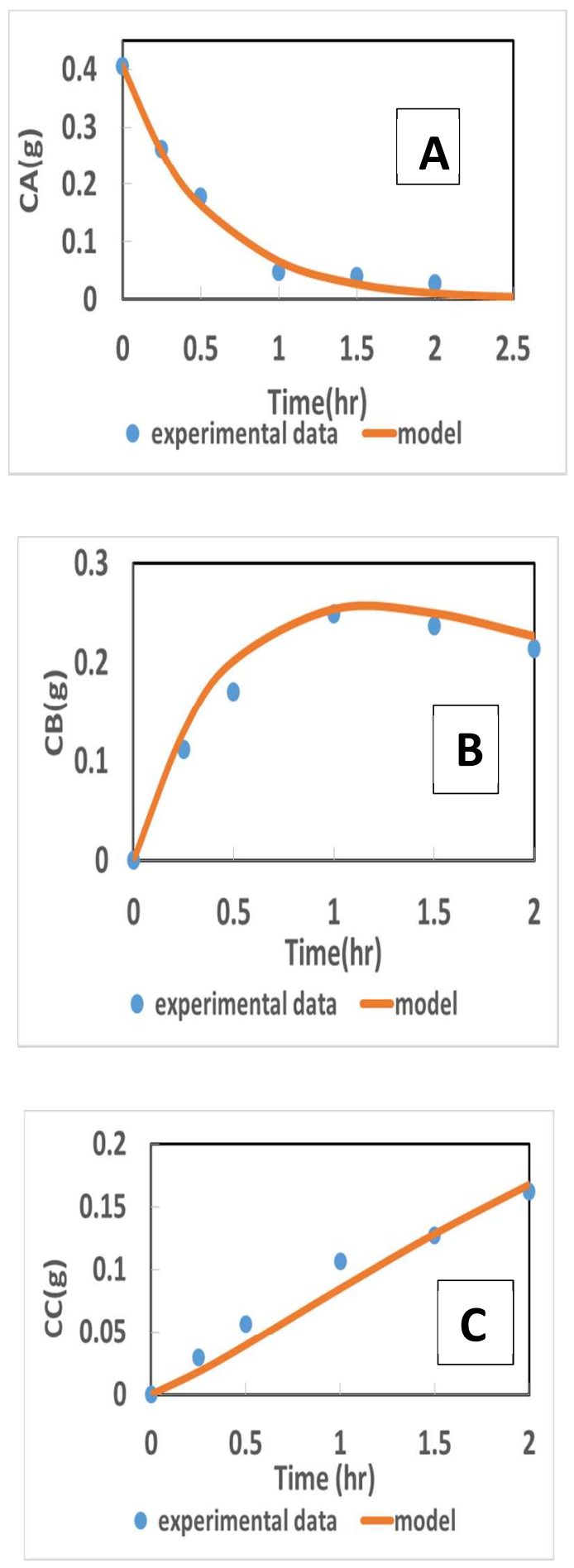

Figure S1 

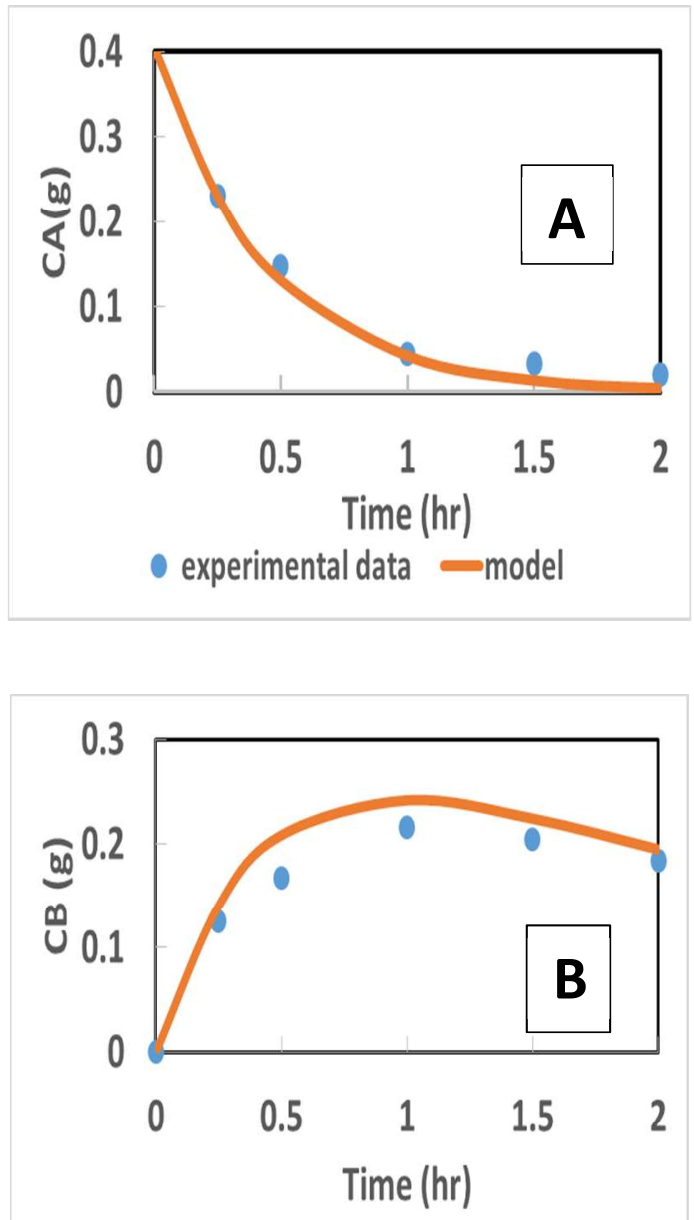

- experimental data -model

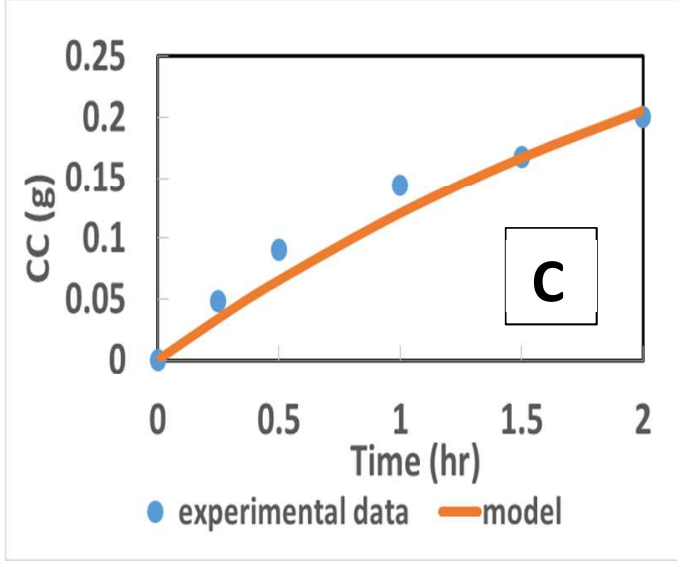

Figure S2 